ARTIGOS 


\section{Antíoco I, grande como Ciro e Dario, ou a realeza babilônica revisitada: uma abordagem intercultural de três textos régios antigos}

Henrique Modanez de Sant Anna* Raul Vitor Rodrigues Peixoto*

Resumo: Este artigo propôe identificar elementos comuns no cilindro de Ciro, na inscrição de Behistun e no cilindro do templo de Ezida, em Borsipa, ou cilindro de Antíoco², como forma de compreender as apropriações Aquemênidas e Selêucidas da tradição monárquica babilônica. Tais apropriações indicariam, em termos históricos, as principais estratégias de legitimação de Dario (o primeiro Grande Rei a aderir ao Zoroastrismo) e Antíoco I, cujo poder repousava tanto na descendência de Seleuco quanto na participação ativa do rei em costumes políticos e religiosos babilônicos.

Palavras-chave: Selêucidas. Zoroastrismo. Império Persa.

\section{Introdução}

Quando Alexandre derrotou Dario III em Gaugamela, ele não apenas aniquilou as chances persas de organizar uma resistência militar efetiva contra o invasor macedônio, mas também encerrou uma linha dinástica que remontava, segundo informaçôes contidas na

\footnotetext{
* Professor adjunto do PPG em História da Universidade de Brasilia - UNB. Doutor em História pela mesma instituição com estágio de pesquisa na Universidade da Califórnia, Berkeley. E-mail: henriquemodanez@gmail.com.

${ }^{* *}$ Professor titular do Instituto Federal de Educação, Ciência e Tecnologia de Goiás - IFG. Doutorando em História pela Universidade de Brasília - UNB. E-mail: soliduspetrus@gmail.com.
} 
inscrição de Behistun (cf. infra), ao primeiro Aquemênida. Alexandre, na ocasiáo, um misto de rei dos macedônios, hegemon dos gregos, soberano dos egípcios e Grande Rei, ao mesmo tempo em que havia assegurado a supremacia militar em território asiático, não possuía a legitimidade de um monarca proclamado pelas tradiçóes locais. Talvez essa condição justifique as inúmeras revoltas enfrentadas por ele nos últimos anos de sua vida. Com efeito, entre 326 e 323 a.C., Alexandre teve que lidar com a travessia desastrosa do deserto de Gedrósia (atual Baluchistão), a revolta de alguns sátrapas (macedônios e iranianos), a fuga de Hárpalo, tesoureiro do rei, que tomou cinco mil talentos do tesouro real e fugiu com uma tropa de mercenários para Atenas, e a morte de Heféstion, um dos Companheiros (hetairoi) mais próximos de Alexandre (GREEN, 1991, p. 433-437; MOSSÉ, 2004, p. 45-46).

Em 323 a.C., logo após a morte do rei, disputas entre seus generais irromperam como seus "jogos fúnebres" (DIODORO DA SICÍLIA, Biblioteca Histórica XVIII, 1), até que certo equilíbrio político pudesse ser atingido por volta de 301 a.C., com os resultados decisivos da batalha de Ipso. Nas províncias orientais (aproximadamente os atuais Afeganistão, Irã, Iraque, Síria e Líbano, além de partes da Turquia, Armênia, Turcomenistão, Uzbequistão e Tajiquistão) estabeleceu-se Seleuco, fundador da dinastia que herdou seu nome e que existiu até 64 a.C., quando o general romano Pompeu transformou a Síria em província romana.

De modo geral, os reis helenísticos mesclavam práticas integrantes de uma imitatio Alexandri (STEWART, 1993, p. 150-157) e apropriaçóes de tradiçóes monárquicas orientais mais antigas, com o objetivo de legitimar sua posiçáo tanto pelo princípio da doriktetos chora (lit. "terra conquistada pela lança", algo herdado das conquistas militares de Alexandre e de sua monarquia pessoal) quanto pela identificação com reis orientais que os antecederam, satisfazendo assim muitas das expectativas das elites sacerdotais locais. Entre os primeiros Selêucidas, Antíoco foi o grande responsável por conduzir a segunda estratégia de legitimação; de fato, ele pretendia fazer-se representar como um novo Aquemênida, legítimo como Ciro e Dario I, conforme argumentaremos ao longo deste artigo, por meio da análise comparada dos conteúdos do cilindro de Ciro, da inscrição de Behistun e do cilindro de Antíoco. 


\section{Eu sou Dario, o grande rei, o rei dos reis: a ideologia imperial aquemênida à luz do zoroastrismo}

Quando Ciro conquistou a Lídia, em 546 a.C., ele conquistou, por extensão, as cidades gregas da costa da Ásia Menor, antes subjugadas pelo rei lídio, Creso. Tendo expulsado de vez a monarquia dos medos, surgida por sua vez no século VIII a.C. e centrada no território que hoje corresponde ao norte do Irã, Ciro permitiu que o reino da Pérsia se transformasse em um verdadeiro império (BRIANT, 2002, p. 31-44; BRIANT, 2013, p. 1-3). Dario I, portanto, pôde se consagrar como herdeiro e soberano de um vasto território imperial, que se estendia do Afeganistão à Turquia (de leste a oeste) e do sul da antiga Uniâo Soviética ao Egito (de norte a sul) (MARTIN, 2000, p. 97).

Devido à imensidão do Império Persa, o Grande Rei contava com uma estrutura administrativa formada por províncias, ou satrapias, governadas por um sátrapa, que agia em nome do Grande Rei, embora com grande autonomia política. Nessa estrutura mista de centralização do poder em uma única figura, mas com grande respeito ao poder autônomo dos governadores das províncias (o único meio de administrar território tão vasto e heterogêneo), o Grande Rei tornou-se um dos mais ricos - se não o mais rico - dentre todos os reis de seu tempo (BRIANT, 2013, p. 178-180).

Sua riqueza e seu poder eram aspectos enfatizados nas fontes persas (cf. infra, no cilindro de Ciro e na inscrição de Behistun) e gregas, bem como deviam-se, portanto, ao menos desde Dario e de acordo com a ideologia imperial persa, ao direito concedido por Ahuramazda ${ }^{3}$ - divindade suprema do Zoroastrismo.

O Zoroastrismo, originalmente chamado de Mazdaísmo, é uma prática religiosa bastante antiga que remonta ao final do segundo milênio a.C. O nome pelo qual ficou conhecida no ocidente é derivado da versão grega do nome de seu fundador: Zoroastro. "Zarathustra", conforme grafia avéstica, é figura central na religiáo; seu profeta, de acordo com a tradição religiosa supracitada, teria recebido diretamente de Ahuramazda a inspiração para compor os Gathas, hinos que constituem o cerne da tradição Zoroastrista (cf. HINTZE, 2009, p. 3). Esta prática de composição era levada a cabo por clérigos comumente chamados de "poetas-sacrificantes", que, por meio de técnicas de 
meditação e/ou indução química, pensavam alcançar contato direto com as divindades e delas receberiam visóes e inspiração métrica dos hinos compostos. Essa prática, ao que tudo indica, é muito antiga entre povos de origem indo-europeia, o caso das tribos que primeiro adotaram o Zoroastrismo (SKJÆRVØ, 2006, p. 12-13).

A figura de Zaratustra é controversa, sendo considerado tanto um reformador religioso como o fundador de uma nova religião. Isto ocorre devido à permanência de muitos aspectos da antiga tradição iraniana, relacionada aos textos Védicos, e da tradição Bramânica. No entanto, vários desses aspectos foram drasticamente ressignificados por Zaratustra, a exemplo do fato de os deuses Védicos, os Devas, passarem a ser considerados demônios, dignos de repulsa, inimigos de toda boa criação de Ahuramazda (SKJÆRVØ, 2006, p. 18, p. 25). Sua própria existência (a do profeta) é posta em questáo por alguns pesquisadores, e amplo debate é travado a respeito. ${ }^{4}$

Zaratustra, por questôes filológicas, não pode ter vivido e pregado no Irã ocidental. Assim, a religião em questão não surgiu entre medos e persas, considerados iranianos ocidentais, mas sim entre os iranianos orientais. A fé zoroastrista entâo teve de se deslocar juntamente com as tribos do sul das espetes da atual Rússia (a leste do Volga), para assim chegar à porção oeste do Irã por meio da migração pastoril. Em seguida, a fé Zoroastrista foi amplamente adotada por uma classe sacerdotal medo-pérsica que, ao que tudo indica, já existia anteriormente à chegada do próprio Zoroastrismo: os Magi (ou Magos), que acabaram se tornando os clérigos zoroastristas mais conhecidos no ocidente, sendo citados por diversas fontes gregas (BOYCE, 1990, p. 7-8).

Uma vez adotado pelos persas, os ensinamentos Zoroastristas mantiveram seu cerne e puderam ser sumarizados em um princípio triplo que reflete o caráter moralizante e de responsabilidade individual do praticante: "[...] nutrir bons pensamentos, falar boas palavras, realizar boas ações” (WEST, 2010, loc. 260). Esta fórmula está intimamente ligada ao papel dos seres humanos na cosmovisão Zoroastrista: de acordo com ela, os seres humanos foram criados por Ahuramazda para ajudá-lo a suster o princípio denominado $A s h a$, princípio universal de ordem e verdade, em oposição a Angramanyu (do avéstico "Angra" = tolo, maligno e "Manyu" = espírito, inspiração), o ser maligno que preza pelo avanço do Druj, princípio do caos e da 
mentira que visa à subversão do $A$ sha estabelecido inicialmente por Ahuramazda. Dessa forma, sempre que o homem praticasse boas açóes, falasse a verdade, nutrisse o bem e realizasse os rituais da religião, ele estaria garantindo que o Asha de Ahuramazda prevalecesse sobre o Druj de Angramanyu (KASSOK, 2013, p. 196).

$\mathrm{O}$ entendimento desse aspecto da cosmovisão Zoroastrista é fundamental para entendermos o sentido da apropriação levada a cabo pelos reis Aquemênidas. Em outras palavras, é como máximo mantenedor do princípio denominado Asha que Dario se faz representar, na inscrição de Behistun, como rei legitimado por Ahuramazda (COHN, 1999, p. 104). Além disso, a mítica Zoroastrista é povoada por narrativas que relacionam a religiáo ao poder monárquico. $\mathrm{O}$ mito de Yima é bastante emblemático a esse respeito, pois mostra como Ahuramazda inicialmente patrocinava o poder real, concedendo ao seu detentor seu domínio hipostasiado: o Khavarenah. O reino de Yima seria, portanto, uma execução perfeita do princípio Asha (BOYCE, 1990, p. 29-30).

Dada a antiguidade da tradição oral Zoroastrista, pode-se inferir que a imagética mítica da religiâo sempre dispôs desta aproximação entre Ahuramazda e o poder monárquico, não necessitando assim adaptá-la ao contexto da monarquia Aquemênida. Entretanto, havia um aspecto do Zoroastrismo que entrava em conflito direto com os interesses de legitimação de um império tão extenso: seu conteúdo amplamente apocalíptico. De fato, Zaratustra aguardara o fim do "tempo limitado" para pouco depois de sua morte, quando ocorreria a implantação da "Transformação Maravilhosa". Trata-se do domínio do Saoshyant, uma figura soteriológica divina que restauraria o mundo tal como ele era antes do ataque perverso de Angramanyu. Este mesmo Saoshyant, por fim, ressuscitaria todos os homens e organizaria o tribunal onde todos seriam julgados de acordo com seu compromisso com Asha ou Druj, decretando suas respectivas sentenças eternas.

Essa esperança escatológica que poderia se concretizar a qualquer momento foi de grande importância para a sobrevivência do Zoroastrismo em tempos de perseguição, como no caso da invasão de Alexandre. Pode-se inferir, assim, do próprio texto de alguns Gathas, que em seu contexto o próprio Zaratustra sofria com ataques de bandos de ladróes de gado extremamente violentos, situação da qual 
se retira a explicação para o conteúdo bastante ético e moralizante dos hinos (WEST, 2010, loc. 460).

A questão passa a ser, especificamente, a da impossibilidade de harmonizar a esperança escatológica latente com a proposta de um reino longo e próspero, no momento em que Dario passou a se identificar como legitimado por Ahuramazda. De acordo com a fé Zoroastrista, todos os reinos terrenos poderiam ser drasticamente interrompidos por determinação do próprio Ahuramazda. Sendo assim, não há como julgar se, conscientemente ou não, os clérigos reais, por volta da primeira metade do séc. IV a.C., abandonaram a escatologia Zoroastrista ortodoxa em prol de uma reinterpretação que ficou conhecida como Zurvanismo. Conforme essa nova hermenêutica escatológica, elaborada em um novo contexto de prosperidade econômica e domínio político, a urgência do juízo final de Ahuramazda foi perdida. Os tradicionais esquemas para o cálculo aproximado da vinda de Saoshyant, que instauraria a "Transformação Maravilhosa", foram modificados para um confortável intervalo de mais de dois mil anos após a aproximação de Dario com as práticas Zoroástricas.

Dario náo somente passou a ter um império garantido pela graça do próprio Ahuramazda, como também conquistou para si e para a sua descendência mais dois mil anos antes de ter de passar finalmente o bastáo do poder universal para o Saoshyant.

As pretensóes universalistas do Zoroastrismo, que tão bem saciavam as necessidades ideológicas de uma casa imperial como a Aquemênida, advinham justamente de sua perspectiva escatológica que profetizava o juízo final para todos os homens. $\mathrm{O}$ aspecto da urgência do juízo final fora suprimido, contudo o alcance universal do princípio denominado $A s h a$, que legitima a lei em combate ao princípio Druj, que por sua vez legitima o uso da força, permaneceu talhado no penhasco de Behistun.

\section{A inscrição de Behistun e sua relação com o cilindro de Ciro}

Inscrita em persa antigo, babilônio e elamita na beira de um penhasco situado no norte do Irá, a inscrição de Behistun registra 
os feitos de Dario I. Seu conteúdo denuncia a usurpação de um falso rei, Gaumata, tratado como representaçáo do Druj. Dario, escolhido por Ahuramazda, seria o instrumento pelo qual a divindade fez prevalecer o Asha, conferindo-lhe o governo de um império que se estendia da Jônia (costa da Turquia) às fronteiras da Índia, de oeste a leste, e das estepes russas ao Egito, de norte a sul. Mais do que simplesmente evidências para uma história política do reino de Dario, a inscrição funciona como uma das principais fontes para a ideologia imperial Aquemênida.

Dario não foi o primeiro a considerar a difusão e a perpetuação dos seus feitos por meio da construção de monumentos ou objetos sagrados. De fato, Ciro, antes dele, teve seus feitos registrados em um cilindro, que continha um texto cuneiforme escrito por sacerdotes de Marduk, a principal divindade da Babilônia. Nele, a conquista da cidade pelos persas, em 539 a.C., foi apresentada como parte dos planos de Marduk, que lançou mão de Ciro como ferramenta divina para punir Nabônides, o último rei babilônio, alegando que ele negligenciou de modo sério os cultos e demais festivais tradicionais:

Eu sou Ciro, o rei do universo, o Grande Rei, o rei poderoso, o rei da Babilônia, o rei da Suméria e da Acádia, o rei dos quatro cantos do mundo, o filho de Cambises, o Grande Rei, o rei da cidade de Anshan, o neto de Ciro, o Grande Rei, o rei da cidade de Anshan; o neto de Teíspes, o Grande Rei, o rei da cidade de Anshan (Cilindro de Ciro, linhas 20-21; DARYAEE, 2013, p. 78-84).

A inscrição de Behistun seguia as mesmas formulações do cilindro de Ciro, o fundador do Império Persa. Como Ciro, Dario I apresentava-se imbatível, legítimo e no direito de formar um império universal:

Eu sou Dario, o Grande Rei, o rei dos reis, o rei da Pérsia, o rei das províncias, o filho de Histaspes, o neto de Arsames, o Aquemênida. 
Diz Dario, o rei - meu pai era Histaspes; o pai de Histaspes era Arsames; o pai de Arsames era Ariaramnes; o pai de Ariaramnes era Teíspes; o pai de Teíspes era Aquemenes. Diz Dario, o rei-com base nessa linhagem, somos chamados de Aquemênidas; descendemos desde os tempos antigos; desde os tempos antigos nossa família foi uma família de reis.Diz Dario, o rei - antes de mim, oito de minha raça foram reis; eu sou o nono; nove de nós foram reis em sucessão.Diz Dario, o rei - pela graça de Ahuramazda eu sou rei; Ahuramazda garantiu-me o Império (Inscrição de Behistun, coluna 1, linhas 1-5; GODOLPHIN, 1942, p. 623).

$[\ldots]$

Diz Dario, o rei - nesses territórios, eu tratei com generosidade o homem que se mostrou bom. Quem quer que tenha se mostrado mau, no entanto, eu tratei de eliminar. Pela graça de Ahuramazda, esses são os territórios pelos quais minhas leis têm sido observadas. [...]Diz Dario, o rei - Ahuramazda garantiu-me o Império. Ahuramazda veio em meu auxílio, de modo que eu pudesse conquistar esse Império. Pela graça de Ahuramazda, eu detenho o Império (Inscrição de Behistun, coluna 1, linhas 8-9; GODOLPHIN, 1942, p. 624).

Assim, as expectativas de Dario, como as de Ciro, estavam voltadas para o controle de um império universal, mas diferentemente do último, Dario apresentava-se também como rei legítimo, pela aproximação com Ahuramazda. De acordo com a ideologia imperial persa, ao menos desde Dario, o Grande Rei náo poderia se contentar com um território restrito, pois sua condição como arauto da divindade Zoroástrica dependia do controle e da manutenção da ordem em todo o mundo, em regióes nas quais o mal seria suprimido para o triunfo do bem (cf. supra), o que se confunde, em termos políticos, com a supressão dos inimigos do Grande Rei. O vínculo da casa real com o Zoroastrismo significava, na prática, um convite para o expansionismo militar, embora a submissão pelo reconhecimento da condição quase divina do rei fosse algo igualmente desejável. 


\section{Eu sou Antíoco, o grande rei: as apropriaçóes selêucidas da antiga monarquia babilônica}

No período helenístico, mais precisamente após a autoproclamaçáo dos Sucessores de Alexandre e da batalha de Ipso (301 a.C.), Seleuco anexou aos territórios que já possuía outras partes do Irã,o norte da Síria e da Mesopotâmia, a Armênia e o sul da Capadócia. Antes da batalha de Ipso, incursôes já haviam sido feitas em território indiano, via Báctria, contra Chandragupta, inimigo dos macedônios desde a morte dos sátrapas que Alexandre deixara na regiáo. Todas essas conquistas militares justificavam-se para Seleuco pelo fato de o rei encaminhar o que para ele representava uma verdadeira restauração do Império Macedônico perdido. De fato, por volta de 280 a.C., em se tratando do território asiático e excluindo-se o Egito e partes da Ásia Menor, o Império Selêucida em muito se assemelhava ao de Alexandre, no final de sua expedição (SHIPLEY, 2000, p. 286-287).

Quando da morte de Seleuco, o poder imperial já era compartilhado com seu filho, Antíoco, mais precisamente desde 292 a.C. Antíoco teria sido publicamente apresentado (para a assembleia dos soldados, como na tradição macedônica) por Seleuco como seu sucessor legítimo nessa data, considerando-se todas as suas qualificaçóes morais para o cargo, conforme registro feito por Apiano:

Então ele convocou seu exército, que talvez estivesse finalmente suspeitando de algo, e contou aos homens suas façanhas e lembrou a extensão de seu império, mostrando que ele havia ultrapassado o tamanho dos impérios dos demais Sucessores de Alexandre, e dizendo que, agora com idade avançada, era-lhe difícil governar o Império por causa de sua extensão. "Eu desejo", disse aos homens, "dividi-lo, levando em conta os seus interesses, e cedendo agora uma parte dele aos que me são mais queridos. É oportuno que todos vocês, que avançaram rumo à construçáo de império táo vasto sob meu comando desde o tempo de Alexandre, colaborem comigo em tudo. Os mais queridos e aptos a reinar são meu filho adulto e minha mulher. E como eles são jovens, eu rogo para que logo possam ter filhos que os ajudem a guardar o 
Império. Eu os uno em matrimônio em sua presença e os envio neste momento como soberanos das províncias altas. A lei que imponho a vocês não são os costumes dos persas e de outros povos, mas a lei comum, a que emana do rei com justiça." Assim que disse isto, o exército aclamou-o como o maior dos reis dentre os Sucessores de Alexandre e como o melhor dos pais (APIANO, 1912, s.p).

A citação de Apiano esclarece muito sobre um aspecto da dominação Selêucida, especialmente quando considera-se a Ásia Menor região suprimida neste artigo em função do seu escopo. De fato, como enfatizado por Ma (1999), a dominação Selêucida estava baseada em dois princípios: o direito de conquista e o direito de herança. Ambos mesclavam-se, por exemplo, na indicaçáo do herdeiro e sucessor de Seleuco, o que o rei decidiu fazer perante as tropas, das quais parte de sua autoridade legítima emanava, como um novo Alexandre.

Se, por um lado, as fontes literárias para o período (Diodoro, Políbio e Apiano, destacado anteriormente), as inscriçóes reais e os decretos das cidades registram certa moral pessoal como qualificadora dos reis Selêucidas, por outro, os textos oficiais babilônicos, frequentemente negligenciados pela historiografia, ilustram a ideologia da monarquia Selêucida em contexto babilônico. Apesar do estado fragmentário dessas evidências, muitas delas demonstram a preocupação do rei em participar de rituais que tradicionalmente contavam com a participação do rei babilônio, a exemplo do festival do Ano Novo babilônico (KUHRT; SHERWIN-WHITE, 1993, p. 130-131).

Além dos textos oficiais babilônicos, a mudança nos modos de legitimação dos Selêucidas é evidente nas moedas cunhadas no período. Seleuco I e Ptolomeu I importaram muitos dos traços presentes no retrato de Alexandre (embora os tenham transposto para uma idade mais avançada); as próximas geraçóes de reis helenísticos, no entanto, adotaram uma estratégia que transitava entre os vínculos com os ancestrais macedônios, por meio do culto dinástico, e a representação de suas imagens de modo similar àquelas dos soberanos locais que os antecederam. Nesse sentido, é fulcral perceber que o retrato numismático de Seleuco II (246-226 a.C.), por exemplo, não traz os mesmos traços que os encontrados em seus antecessores; em vez de representar força e 
tensão, passa a representar reserva, quietude e distância, características tipicamente mesopotâmicas e egípcias (FLEISCHER, 1996, p. 31).

Outra fonte importante para a identificação dos Selêucidas com tradiçôes monárquicas mais antigas é o chamado cilindro de Antíoco, ou cilindro do templo de Ezida, em Borsipa, cidade próxima a Babilônia, datado de 268 a.C. Neste artigo, o cilindro é a principal fonte analisada com esse propósito, não apenas por sua importância para a compreensão histórica dos vínculos artificiais estabelecidos entre Selêucidas (especificamente Antíoco I) e Aquemênidas, mas principalmente porque contém imitaçóes das formulaçôes encontradas no cilindro de Ciro e na inscrição de Behistun, como meio de representar Antíoco como Ciro e Dario I. ${ }^{5}$

\section{O cilindro do templo de Ezida, em Borsipa (268 a.c.)}

Em 1991, dois anos antes de seu supracitado livro sobre os Selêucidas, Kuhrt e Sherwin-White esclareceram questóes referentes aos métodos que podem ser usados para a crítica dessa fonte selêucida, situando-a em seu cenário sociopolítico, e demonstraram como ela serviu para modificar substancialmente as visóes de historiadores das décadas anteriores sobre a interação dos Selêucidas com súditos não gregos. Segundo as autoras, parte da historiografia interessada na história dos reinos helenísticos tentou diminuir o papel e o caráter dos Selêucidas como governantes imperiais: "de acordo com esta abordagem", insistem, "[...] os Selêucidas não se mostravam ativamente interessados nas áreas orientais do império e tinham pouco interesse pelos vários súditos não-gregos" (KUHRT; SHERWINWHITE, 1991, p. 72). Neste mesmo espírito, o cilindro de Antíoco foi interpretado como documento que registra o interesse Selêucida apenas por Ezida, em Borspisa, desprezando todo o resto dos territórios orientais, ou ainda as expectativas políticas das elites locais babilônias. A construção de Selêucia no Tigre seria o indício cabal desse desinteresse da casa real pela velha Babilônia, que deveria ser gradualmente abandonada.

Desde a reavaliação feita no importante artigo de Sherwin-White e Kuhrt, o cilindro de Antíoco passou a ser visto de modo mais 
positivo como fonte para a história Selêucida, especialmente quando são levados em consideraçáo a ideologia da casa real e sua política com relação às elites babilônicas. Neste artigo, o conteúdo do cilindro de Antíoco é colocado em comparação direta, em uma abordagem intercultural, com as formas de representação dos Aquemênidas, de modo a ilustrar os vínculos artificiais criados pelos Selêucidas com o passado imperial persa. Em outras palavras, formulaçóes na representação e na legitimação dos Aquemênidas, de Ciro a Dario, foram repetidas em tempos helenísticos, particularmente por Antíoco I, o que torna inevitável a associação dos reis persas anteriores à expedição de Alexandre com os Selêucidas do século III a.C.

As primeiras linhas do cilindro são emblemáticas a esse respeito:

Eu sou Antíoco, o Grande Rei, o rei poderoso, o rei do universo, o rei da Babilônia, o rei de todos os territórios, o cuidador dos templos de Esagila e Ezida, o primogênito do rei Seleuco, o macedônio, rei da Babilônia.

Nebo, eminente filho, o mais sábio dentre os deuses, esplêndido e digno de toda a adoraçáo, primogênito de Marduk, filho de Erua, a rainha que modelou toda a criação, lança teu olhar benevolente sobre mim e torna - sob seu eminente e irrevogável comando - a derrocada do território de meu inimigo, a satisfação de todos os meus desejos contra os meus adversários, a predominância constante, um reino de justiça, um governo ordenado, anos de felicidade e prole suficiente sua benção permanente para a realeza conjunta de Antíoco e seu filho, o rei Seleuco (AUSTIN, 2006, p. 304). ${ }^{6}$

Assim, Antíoco, como Ciro e Dario séculos antes dele, ao dedicar-se ao templo de Ezida, mostrava-se não apenas preocupado com Borsipa, mas também com os demais territórios orientais, pois ele era "o rei dos reis, o rei do universo, o rei de todos os territórios", o protegido dos deuses. A análise dos títulos empregados, portanto, revela um "programa político padrão": as aspiraçóes babilônicas ao 
império universal, levadas a cabo pelo rei do universo (shar kishshati) e pelo rei dos territórios (shar matati); o poder e a legitimidade do governante, simultaneamente o rei poderoso/legítimo (sharru dannu) e Grande (sharru rabûu). Considerando-se a ideologia constante desses documentos, que remonta às antigas expressôes da antiga realeza babilônica, via dinastia Aquemênida, parece correto dizer que estamos diante de uma "[...] monarquia moral, mas ao mesmo tempo enérgica e imperialista, devotada aos deuses babilônios, e deles dependente" (KUHRT; SHERWIN-WHITE, 1991, p. 78-79).

\section{Consideraçóes finais}

Uma das características do poder monárquico helenístico era a vagueza intencional do título real, o que funcionava como convite ao expansionismo militar. Da mesma forma, Dario, no século VI a.C., na inscrição de Behistun, registrou seu direito ao império universal, não com base na natureza pessoal de seu poder monárquico, mas na representação direta de Ahuramazda no mundo dos homens. Curiosamente, Antíoco I fez-se representar, no cilindro do templo de Ezida, em Borsipa, como servo de Marduk, a mesma divindade honrada por Ciro em seu cilindro, o que remonta à tradição monárquica ligada ao depósito desse tipo de objeto (o cilindro) em templos babilônicos, sem, no entanto, ignorar as aspiraçóes universais de Dario.

Antíoco, então, como rei helenístico, apostou no sincretismo de duas práticas político-religiosas babilônicas: o depósito de um cilindro em templos babilônios pelo rei legítimo, em imitação de Ciro, e o direito ao império universal, herdado de reis babilônios anteriores e especialmente de Dario, após sua incorporação de algumas práticas do Zoroastrismo. A preocupação de Antíoco em se fazer representar como rei legítimo segundo as tradiçóes monárquicas babilônicas, por fim, ilustra que a satisfação das expectativas das elites locais (seus súditos mais poderosos) era uma das principais preocupaçóes dos reis helenísticos, contrariando a ideia de que uma elite militar grega/ macedônica governava territórios helenísticos apenas com base na força militar expressa. 


\section{ANTIOCHUS I, AS GREAT AS CYRUS AND DARIUS, OR THE BABYLONIAN KINGSHIP REVISITED: A CROSS- CULTURAL APPROACH OF THREE ANCIENT ROYAL TEXTS}

Abstract: This article aims at identifying shared elements in the Cyrus cylinder, the Behistun inscription and the Borsippa cylinder from the Ezida Temple, also called "Antiochus cylinder", as a means to understand Achaemenid and Seleucid manipulation of Babylonian monarchical tradition. Such manipulation would reinforce the main legitimizing strategies by Darius (the first Great King to adopt Zoroastrian faith) and Antiochus I, whose power owed both to his family ties to Seleucus I and, simultaneously, in the active participation in Babylonian political and religious practices related to divinization of kingship.

Keywords: Seleucids. Zoroastrism. Persian Empire.

\section{Notas}

${ }^{1} \mathrm{O}$ cilindro de Ciro, escavado em 1879 pelo arqueólogo Hormuzd Rassam e atualmente em exposição no British Museum, é uma das fontes princiáis para a conquista da Babilônia pelo rei persa Ciro, o Grande. Nele, estáo documentados (em acadiano) a marcha pacífica do exército persa sobre a cidade e o governo alegadamente tirânico de Nabonido, o último rei da Babilônia. Por isso, Ciro é apresentado como escolhido de Marduk, divindade ligada àquela cidade, que teria abandonado seu último rei, um tiranopor excelência, em favor do invasor estrangeiro. ${ }^{2}$ Da mesma forma que o Cilindro de Ciro, o cilindro de Antíoco (cujo texto cuneiforme está igualmente sob a guarda do British Museum) é uma das principais fontes para a história da Babilônia. Nele, encontra-se descrita a reconstrução do templo de Ezida por Antíoco I, filho de Seleuco Nicator, em 268 a.C., bem como sua preocupação em obter a proteção divina para seu governo alegadamente legítimo. A particularidade desse cilindro reside especialmente no fato de ser a última inscrição real em cuneiforme, e curiosamente a única realizada por um monarca selêucida. ${ }^{3}$ Do avéstico "Ahura Mazdā". Em certos textos a divindade pode aparecer simplesmente como Mazdā, ou até Mazdā Ahura. Estes dois epítetos, que formam o nome da divindade, referem-se, segundo Skjærvø, às funções da divindade. $\mathrm{O}$ significado do termo "Ahura" é incerto, mas aceita-se como traduçóes aproximadas "Senhor" ou "Engendrador", tendo como base o texto do Avesta. "Mazdā", por sua vez, pode ser traduzido como "aquele que póe todas as coisas em sua mente" (SKJÆRVØ, 2006, p. 1). Boyce (1990, p. 9) apresenta uma possível traduçáo mais objetiva para os epítetos: "Senhor da Sabedoria".

${ }^{4}$ Há pesquisadores que não acreditam na existência de Zaratustra como personagem histórica, classificando-o como uma figura ficcional. Este é o caso de 
Gnoli (1972, p. 557), que questiona, por exemplo, a ausência dos nomes dos pais de Zaratustra, ou qualquer outra evidência fora dos textos. A posição adotada pelos autores é a de que há dois Zaratustras: o profeta concreto, representado de forma mais realista no Avesta antigo e um mítico/heroico, representado no Avesta jovem com características sobre-humanas. (SKJÆRVØ, 2006, p. 51-54). ${ }^{5}$ Outra questáo sobre o cilindro de Antíoco diz respeito ao objeto propriamente dito, e não ao texto nele inscrito. Os cilindros eram depositados apenas em estruturas públicas, especialmente em templos, sendo um traço muito peculiar da tradição monárquica mesopotâmica (o rei era sempre o depositário, visto que seus feitos políticos e militares representariam a vontade do deus homenageado). ${ }^{6} \mathrm{O}$ Seleuco anunciado no cilindro não é Seleuco I, mas o primogênito de Antíoco I, regente com o pai de 279 a.C. a 268 a.C., quando foi assassinado por ele, acusado de liderar uma conspiração.

\section{Referências}

APIANO. Guerras Estrangeiras XI, 61. Cambridge, MA; London: Harvard University Press, 1912.

AUSTIN, Michel. The Hellenistic World from Alexander to the Roman Conquest. A Selection of Ancient Sources in Translation. Cambridge: Cambridge University Press, 2006.

BOYCE, Mary. Textual Sources of the Study of Zoroastrism. Chicago: Chicago University Press, 1990.

BRIANT, Pierre. The Land-Collectors: Cyrus the Great and Cambyses (559-522). In: _. From Cyrus to Alexander. A History of the Persian Empire. Warsaw: Eisenbrauns, 2002. p. 31-44.

. Cyrus the Great. In: DARYAEE, Touraj (Org.). Cyrus the Great. An Ancient Iranian King. Santa Monica: Afshar, 2013. p. 1-16.

COHN, Norman. Cosmos, Chaos, and the World to Come. New Haven: Yale University Press, 1999.

DARYAEE, Touraj (Org.). Cyrus the Great: an ancient Iranian king. Santa Monica: Afshar, 2013.

DIODORO DA SICÍLIA. Biblioteca Histórica XVIII, 1. Cambridge, MA, London: Harvard University Press, 1947.

FLEISCHER, Robert. Hellenistic Royal Iconography on Coins. In: Bilde, Per (Org.). Aspects of Hellenistic kingship. Aarhus, Oakville: Aarhus University Press, 1996.

Anos 90, Porto Alegre, v. 23, n. 43, p. 269-284, jul. 2016 
GNOLI, Gerardo. Problems and Prospects of the Studies on Persian Religion. In: BIANCHI et al (Orgs.). Problems and Methods of the History of Religions. Leiden: Brill, 1972.

GODOLPHIN, Francis. The Greek Historians, v.2. New York: Random House, 1942. GREEN, Peter. Alexander of Macedon, 356-323 B.C.: a historical biography. Berkeley, Los Angeles, Oxford: University of California Press, 1991. p. 433-437. HINTZE, Almut. Avestan Literature. In: EMMERICH, Ronald.; MACUCH, Maria. The Literature of Pre-Islamic Iran. A History of Persian Literature. London: I.B. Tauris, 2009.

KASSOCK, Zeke. The Greater Iranian Bundahishn A Pahlavi Student's Guide. Fredericksburg: Kassock Bros, 2013.

KUHRT, Amelie; SHERWIN-WHITE, Susan. From Samarkhand to Sardis: a new approach to the Seleucid Empire. Berkeley, Los Angeles, Oxford: University of California Press, 1993.

MA, John. Antiochus III and the cities of Western Asia Minor. Oxford: The University Press, 1999.

MARTIN, Thomas. Ancient Greece. New Haven, London: Yale University Press, 2000.

MOSSÉ, Claude. Alexandre, o Grande. São Paulo: Estação Liberdade, 2004.

SHIPLEY, Graham. The Greek world after Alexander, 323-30 B.C. London, New York: Routledge, 2000.

SKJÆRVØ, Oktor. Introduction to Zoroastrianism. Iranian Studies at Harvard University, 2006, p. 1. Disponível em: http://www.fas.harvard.edu/-iranian/ Acesso em: 16 abr. 2014.

STEWART, Andrew. Faces of Power: Alexander's image and Hellenistic politics. Berkeley, Los Angeles, Oxford: University of California Press, 1993.

Recebido em: 27/ 11/ 2014 Aprovado em: 07/ 07/ 2015 